\title{
As relações públicas no meio-campo da gestäo de marcas nos negócios relacionados ao esporte
}

\author{
Public relations in the midfield of brand \\ management for businesses related to sports
}

Las relaciones públicas en el medio campo de la gestión
de marcas en los negocios relacionados con el deporte

Ary José Rocco Junior

- Doutor em Comunicação e Semiótica pela Pontifícia Universidade Católica de São Paulo (PUC-SP)

- Mestre em Administração pela PUC-SP

- Graduado em Administração Pública pela Fundação Getulio Vargas (FGV-SP) e em Jornalismo pela Faculdade Cásper Líbero

- Professor da Escola de Educação Física e Esporte da Universidade de São Paulo (Eefe-USP)

- Pró-Reitor de Graduação e coordenador dos cursos de Publicidade/Propaganda e Relações Públicas do Centro Universitário Fecap

- Membro do Grupo de Pesquisa em Comunicação e esporte da Sociedade Brasileira de Estudos Interdisciplinares em Comunicação (Intercom)

- Colunista de futebol argentino no programa Jovem Pan no Mundo da Bola, da Rádio Jovem Pan AM

- Tem experiência nas áreas de comunicação e gestão do esporte, atuando principalmente nos seguintes temas: prática do jornalismo, futebol e cultura, marketing esportivo, gestão estratégica da comunicação e comunicação.

- aryrocco@gmail.com 
A escolha do Brasil para sediar os dois eventos mais importantes do cenário esportivo internacional colocou o país, de forma definitiva, no centro dos investimentos financeiros mundiais no universo dos negócios relacionados ao esporte. A progressiva inserção mundial do fenômeno esportivo na indústria do entretenimento e consumo transforma os produtos, os atores e as agremiações esportivas em verdadeiras plataformas para a divulgação e consolidação de marcas nos diferentes mercados de atuação das empresas. O propósito deste trabalho é analisar o papel das relações públicas na mediação da relação entre as marcas e o fenômeno esportivo, focalizando como exemplo concreto o case da Ambev (Companhia de Bebidas das Américas).

PALAVRAS-CHAVE: MARCAS • BRANDING • RELAÇÕES PÚBLICAS • FENÔMENO ESPORTIVO • AMBEV

\section{Abstract}

The choice of Brazil to host the two most important events of the international sports scene has put the country permanently into the center of the world's financial investment in the world of sports-related businesses. The gradual penetration of the global sports phenomenon in the entertainment and consumer industry transforms products, actors and clubs on real platforms for the dissemination and consolidation of brands in the different markets in which the companies operate. The purpose of this study is to analyze, through the case of Ambev (American Beverage Company), the role of PR in mediating the relationship between brands and the sports phenomenon.

KEYWORDS: BRANDS • BRANDING • PUBLIC RELATIONS • SPORTS PHENOMENON • AMBEV

\section{Resumen}

La elección de Brasil como sede de los dos eventos más importantes del escenario deportivo internacional colocó al país, de forma definitiva, en el centro de las inversiones financieras mundiales en el universo de los negocios relacionados con el deporte. La progresiva inserción mundial del fenómeno deportivo en la industria del entretenimiento y consumo transforma a los actores, productos y gremios deportivos en verdaderas plataformas para la divulgación y consolidación de marcas en los diferentes mercados de actuación de las empresas. El propósito de este trabajo es analizar el papel de las relaciones públicas en la mediación de la relación entre las marcas y el fenómeno deportivo, centrándose, como ejemplo concreto, en el caso de Ambev (American Beverage Company).

PALABRAS CLAVE: MARCAS • BRANDING • RELACIONES PÚBLICAS • FENÓMENO DEPORTIVO • AMBEV 
A escolha do Brasil para sediar a Copa do Mundo de 2014 e da cidade do Rio de Janeiro para abrigar os Jogos Olímpicos de 2016, colocou o país no centro da pauta geopolítica internacional e o "produto" esporte, no centro das estratégias mercadológicas das principais organizações empresariais que transacionam no mercado global.

O esporte, pelos atributos positivos que o cercam, vem-se transformando em ferramenta estratégica de marketing para empresas, produtos ou marcas. Qualidade de vida, espírito de equipe, jovialidade, agilidade, lazer, saúde e prazer são apenas alguns dos atributos que o "produto" esporte empresta às organizações, na busca incansável "pelos corações e pelas mentes" dos consumidores de um mercado cada vez mais global e competitivo.

A cultura do esporte mundial, com o apoio dos meios de comunicação de massa, tem experimentado, nas três últimas décadas, crescimento financeiro vertiginoso. Os negócios relacionados ao esporte são, hoje, parte importante da indústria do entretenimento. O sportainment ${ }^{1}$ beneficia, também, segmentos afins, como as indústrias do turismo, da construção civil, da comunicação e da publicidade.

Todo esse cenário serve para dar uma ideia da dimensão global que o esporte, e a cultura que o cerca ocupam na indústria mundial do entretenimento e consumo. Hoje, as grandes empresas, para divulgar suas marcas em seus mercados de atuação, enxergam possibilidades de concentrar suas estratégias mercadológicas na busca do torcedor (consumidor) e na promoção de suas marcas.

Dentro desse contexto, merece destaque a crescente participação de empresas, clubes esportivos, seus patrocinadores, jornalistas e torcedores de futebol, na construção de marcas cada vez mais fortes, relacionadas ao universo do esporte. Um grande número de empresas começou a enxergar nesse universo uma excelente perspectiva de negócio, colocando o evento esportivo como um dos principais vértices da tão propalada indústria do entretenimento e, consequentemente, do consumo.

Porém, para que a relação esporte-empresa funcione adequadamente, com a correta gestão das marcas e seu apropriado relacionamento com o evento esportivo, é necessária a construção de estratégias adequadas de comunicação que permitam, de forma concreta, a identificação plena de uma marca associada ao esporte.

A crescente participação e influência da mídia no esporte faz com que as relações públicas ampliem sua importância nesse universo, deixando de ser uma mera ferramenta de comunicação. A área de relações públicas é parte integrante do composto mercadológico do "produto" esporte e ferramenta estra-

1 Sportainment: indústria do entretenimento esportivo. 
tégica indispensável para a gestão das marcas em seu relacionamento com os agentes esportivos.

A proposta deste artigo é analisar o papel das relações públicas no marketing mix e sua fundamental participação no branding ${ }^{2}$ relacionado ao esporte.

\section{ESPORTE E SUAS MÚLTIPLAS POSSIBILIDADES}

Para entendermos o fenômeno esportivo em seus aspectos mercadológicos, é necessário, antes, analisarmos o esporte enquanto prática social e cultural. Dentro desse prisma, o esporte pode ser definido como

um valor cultural que mobiliza grandes contingentes de pessoas por apresentar em sua essência um forte conteúdo lúdico e emocional. Quer como praticante, como espectadora, parte da população mundial vai aos estádios, quadras e piscinas em busca de um espetáculo ou à procura dos benefícios da saúde que a atividade física proporciona (Nicolini, apud Zenone, 2006, p. 120).

Pela definição acima, podemos perceber que o esporte apresenta, em sua essência, vários elementos que podem ser apropriados pela indústria do entretenimento. O caráter lúdico e emocional do esporte oferece amplas possibilidades que interessam ao "mundo dos negócios". Sempre que o consumidor está "emocionalmente" afetado, maior é a sua propensão a consumir.

Por outro lado, existem várias formas de as pessoas manterem relacionamento com o universo esportivo. Para se gostar de esporte, não há a necessidade de ser um praticante. Tal possibilidade amplia o tamanho do mercado cultural do esporte, dando a ele, hoje, uma dimensão mercadológica global.

O "produto" esporte, em especial por sua aproximação com os meios de comunicação de massa, transformou-se, assim, em excelente ferramenta estratégica de comunicação e marketing. As empresas perceberam que seus consumidores estão muito mais dispostos a consumir seus produtos ou, simplesmente, criar certa simpatia com a marca quando estão vendo ou praticando esporte.

Outra importante característica do fenômeno esportivo que desperta o interesse das grandes corporações é a ampla possibilidade de aproveitamento do esporte do ponto de vista institucional, pelas organizações empresariais.

Segundo Zenone (2006), a prática esportiva pode apresentar três vertentes principais: a do esporte-educação; a do esporte-participação; e a do esporte-desempenho.

2 Branding: gestão de marcas. 
A visão do esporte-educação apresenta forte conotação social. Pode ser definida como o "conjunto de práticas esportivas que tem a escola como espaço físico característico; embora possa e deva ser estendido a todos os ambientes”. As práticas esportivas dessa natureza têm como finalidade o desenvolvimento integral do indivíduo, com a assimilação de valores típicos do esporte (como espírito de equipe, saber ganhar e perder, cooperação e vários outros). O conceito de integração social por meio do esporte é a parte mais visível do esporte-educação.

O esporte enquanto participação também apresenta forte apelo social. Sua prática está relacionada à recreação e aos períodos de lazer das pessoas. A visão contemporânea dessa vertente do fenômeno esportivo está, hoje, vinculada a conceitos socialmente responsáveis, como, por exemplo, o de qualidade de vida. As atividades esportivas dessa natureza reúnem, de forma espontânea ou não, grande número de indivíduos, movidos pelos benefícios da prática saudável do esporte e pelo forte apelo comunitário do fenômeno esportivo.

Com forte apoio dos meios de comunicação de massa, as atividades esportivas caracterizadas pelo elevado rendimento dos atletas e pelo alto sentimento de competição, ganharam o mercado e foram transformadas em um dos alicerces da tão propalada indústria de entretenimento e consumo. A exitosa associação dos meios de comunicação com o fenômeno esportivo conferiu aos eventos dessa natureza o caráter de espetáculo. É no esporte-desempenho que reside, de forma vigorosa, a essência da visão mercadológica das organizações empresarias nas atividades esportivas.

As perspectivas educacionais e de participação presentes no universo esportivo, aliadas à sua penetração no mercado, oferecem às relações públicas um importante papel na comunicação e na construção das marcas relacionadas com o fenômeno do esporte. A união entre esporte e relações públicas será favorecida, também, pelas características peculiares dos produtos esportivos.

\section{O PRODUTO NO ESPORTE E SUAS CARACTERÍSTICAS}

Tratando-se de esporte, como afirmam Morgan e Summers (2008, p. 45),

o produto é o jogo propriamente dito, mas há também alguns componentes intangíveis que precisam ser considerados. Os elementos tangíveis do produto esportivo são os praticantes de determinado esporte, o tipo de competição ou jogo praticado, as decisões de merchandising (camisetas, bonés, equipamentos etc.) e os locais dos jogos. Os elementos intangíveis são as impressões, experiências, emoções e interpretações demonstradas pelas pessoas em relação ao esporte, sejam elas participantes ou não.

Percebemos, assim, que o produto esportivo é altamente inconsistente e imprevisível. Isso o torna atraente, porém dificulta sua comunicação com o mer- 
cado e a construção de seu planejamento estratégico. A falta de previsibilidade do esporte traz ao produto esportivo uma ausência de controle por parte dos gestores que gerenciam seu processo de comunicação.

Como definem Morgan e Summers (2008, p. 45),

os elementos intangíveis do produto esportivo carregam em si muitas das características encontradas nos serviços, a saber:

- perecível - uma vez encerrado um evento esportivo, encerram-se também as possíveis vendas "ao vivo";

- inseparável - os produtos esportivos são simultaneamente produzidos e consumidos quando jogadores, dirigentes e fãs criam o evento que consomem;

- heterogêneo - os produtos esportivos são subjetivos e têm como base a experiência do consumidor ou produtor do esporte e, portanto, cada evento ou experiência esportiva será diferente;

- intangível - muitos elementos do produto esportivo são intangíveis.

Na prática, a relação de produtos relacionados à indústria do esporte é imensa. "Qualquer produto que preencha as necessidades ou desejos de um consumidor quanto a esporte, ginástica ou recreação é considerado produto esportivo" (Pitts; Stotlar, 2002, p.160).

O valor ou beneficio percebido do produto esportivo é uma combinação de elementos tangíveis e intangíveis que são interpretados das mais variadas formas pelos consumidores do esporte. Nas suas decisões de consumo, os consumidores esportivos levam em consideração as demandas concorrentes por seu valor de troca, como dinheiro, tempo, atitude e posse. Como exemplo, podemos ilustrar a decisão, ou não, do consumidor de ir a uma partida de futebol. Essa decisão, na cabeça do torcedor, pode considerar não apenas o desembolso de dinheiro, como os demais custos envolvidos (transporte, refeição, estacionamento etc.), o tempo de viagem, níveis de frustração previstos (filas, trânsito, multidão), outras atividades de lazer deixadas de lado e o custo de oportunidade de ir a essa partida.

A dificuldade, para o profissional de comunicação do esporte, reside em avaliar quando o benefício do produto esportivo é tangível e quando é intangível. Ir a um jogo, por exemplo, é intangível, visto que a experiência de assistir ao esporte será algo de valor difícil de ser mensurado.

Se o produto esportivo, por outro lado, for algo tangível, como um calçado esportivo, o uniforme de uma equipe de futebol ou algum item de merchandising, é muito mais fácil, para o consumidor, definir o valor de troca.

Porém, produtos esportivos oferecidos como entretenimento também são produtos intangíveis. 
Eventos esportivos oferecidos para fins de entretenimento são programados para dia, hora e local específicos e o consumidor tem de estar disponível naquele horário para ir ao local. Um jogo de basquete, por exemplo, pode ser oferecido como produto de entretenimento (Pitts; Stotlar, 2002, p. 215).

O caráter intangível de um evento esportivo faz com ele seja manufaturado e consumido simultaneamente. "O jogo não se produz até que os jogadores o joguem”, segundo Pitts e Stotlar (2002, p. 215).

Assim, o jogo, por seu caráter intangível, deve ser consumido no mesmo instante em que é produzido, ou não é consumido e acaba perecendo. Aquele jogo nunca mais será manufaturado novamente. "Existe, porém, com o uso de recursos de videoteipe, um produto secundário que o consumidor pode comprar e consumir: gravações em vídeo do jogo" (Pitts; Stotalr, 2002, p. 215).

Quando se considera um jogo e seu caráter intangível como produto esportivo, as estratégias de distribuição devem levar em consideração o recinto e as formas de entregar a experiência de comparecer ao jogo para os que não puderam (ou não quiseram) fazê-lo. "É aqui que a mídia se torna um intermediário essencial no canal de distribuição do produto esportivo” (Morgan; Summers, 2008, p. 273).

As características do produto esportivo fizeram crescer a importância da instalação esportiva, como apontam Morgan e Summers (2008), à medida que, cada vez mais, ela é uma parte muito importante da experiência de consumo do esporte e é um dos elementos mais tangíveis dessa experiência. "Estádios esportivos bem projetados podem aumentar a satisfação física e emocional dos espectadores do esporte e desempenhar um papel de distribuição ao facilitar o consumo do evento esportivo a um grande número de pessoas" (Morgan; Summers, 2008, p. 273).

As instalações esportivas foram convertidas, no cenário contemporâneo do esporte, em verdadeiras praças de atuação dos profissionais de relações públicas. A comercialização de lugares privilegiados nos estádios - os camarotes -, bem como de espaços publicitários, é fonte de receita para clubes esportivos e anunciantes. Contribui, também, para a construção positiva da imagem institucional da organização dona da praça esportiva, antes restrita apenas à prática do esporte, hoje verdadeiro espaço para a concretização de grandes negócios empresariais.

O Allianz Arena de Munique (Alemanha), o Wembley Stadium de Londres (Reino Unido) e o Telstra Stadium de Sidney (Austrália), são exemplos desses grandes estádios para diversos fins; e de alta tecnologia que precisam considerar as expectativas dos espectadores e as instalações de apoio em sua comunicação da gestão de entrega do esporte. Como nem todos conseguem ir a um estádio para assistir a seu time ou jogo favorito, a mídia esportiva irá desempenhar seu importante papel na comunicação e distribuição do evento esportivo. 
Como bem esclarecem Morgan e Summers (2008, p. 274), "a mídia permite que os profissionais de gestão esportiva levem seus produtos (o jogo) até várias (algumas vezes, milhões de) pessoas que, do contrário, não teriam como passar por aquela experiência”. Um grande número de indivíduos, em todos os países, não é capaz, por exemplo, de viajar para assistir presencialmente aos jogos da Copa do Mundo de Futebol. Assim, passam a depender da televisão, do rádio, da internet e dos jornais para obter informações sobre o evento e desfrutar da experiência dos jogos do torneio em sua casa.

Esse mesmo processo se aplica "aos profissionais de gestão do esporte cujo produto é um time ou talvez uma associação e prática de um esporte específico" (Morgan; Summers, 2008, p. 274). Em casos como esse, é necessário, que os gestores do esporte estabeleçam estratégias criativas de comunicação e distribuição, via mídia, de seu produto.

A área de relações públicas encontra, então, no esporte território profícuo para desempenhar seu papel com plenitude. O caráter intangível do produto esportivo, quando bem trabalhado pelos profissionais de comunicação, permite a construção de forte apelo institucional para a consolidação de uma marca sólida para produtos e empresas.

\section{BRANDING E RELAÇÕES PÚBLICAS NO ESPORTE}

Os anos 1990 e o início do século XXI, em razão do crescente desenvolvimento tecnológico e da construção de marcas, para empresas e produtos, de caráter global, chamaram a atenção para o branding. Podemos definir branding, ou gestão de marcas, como o processo de construção e administração de uma marca.

O branding procura trabalhar a imagem e a relação que o consumidor tem com um produto, um serviço ou uma empresa. Está basicamente estruturado nas impressões que o cliente constrói da sua relação com a marca e, principalmente, no papel que a marca representa na vida de quem adquire seus produtos ou serviços.

No atual contexto contemporâneo, com a explosão da cultura do consumo mundial, o branding tem adquirido fundamental importância no resultado financeiro das organizações e na definição do valor de mercado de empresas e produtos. As grandes marcas mundiais, de forma geral, estão associadas, mediante construção feita pela correta gestão de sua comunicação com seus stakeholders, a valores que são enxergados de forma positiva pelos seus grupos de interesses.

O branding apresenta, como um dos seus objetivos principais, a associação de um produto, um serviço ou uma empresa com a garantia de qualidade e referência da sua marca no mercado em que atua e até mesmo fora dele. O sucesso desse processo de construção da imagem de uma marca pode ser mensurado 
pela facilidade com que ela é reconhecida, como referência, na cabeça de consumidores, investidores e demais públicos de interesses.

Na década de 1980, o branding era entendido apenas como uma questão de imagem. A comunicação organizacional, ainda pouco identificada com as estratégias de gerenciamento das organizações, era enxergada, de forma geral, apenas com base em ações mercadológicas e de propaganda. A publicidade era a ferramenta principal utilizada pelas empresas para a construção de suas marcas.

A gestão da marca baseava sua construção no princípio da imagem "desejada" pelos consumidores. A estrutura da empresa, suas estratégias e, principalmente, sua cultura, não estavam incorporadas ao processo de desenvolvimento e fortalecimento de sua marca. As organizações nem sempre apresentavam, internamente, as condições necessárias para cumprir e garantir a promessa feita pela publicidade na idealização da marca "desejada” pelos clientes.

O amadurecimento da relação entre consumidores e empresas, ocorrido a partir da metade da década de 1990, transformou a marca, bem como os atributos a ela relacionados, em fatores críticos para o sucesso das organizações.

A onda de fusões e aquisições de empresas, ocorrida nos anos 1990, também contribuiu para que o branding começasse a ser visto como parte do planejamento estratégico das organizações. Em várias dessas transações, realizadas na última década do século passado, investidores pagaram mais de $80 \%$ sobre o valor técnico definido pela contabilidade financeira da época para algumas organizações.

A valorização das marcas, incompatível com a estrutura patrimonial das empresas, transformou o branding em elemento estratégico para as organizações. A questão não era mais apenas de imagem. As marcas passaram a ser um ativo ou patrimônio das empresas, com marcante participação nos resultados econômicos e financeiros das corporações.

Assim como o esporte, as marcas, em seu processo de construção e identificação com seus públicos de interesse, passaram a incorporar uma série de elementos intangíveis, difíceis de serem mensurados pelas técnicas contábeis e financeiras da época. Por outro lado, a performance financeira das empresas passou a refletir, de forma clara, para os stakeholders, o resultado do relacionamento das marcas com seus públicos. As marcas mais leais com seus consumidores passaram a ser, reconhecidamente, mais valorizadas financeiramente em seus mercados. Essa é a principal razão pela qual, hoje, encontramos organizações que apresentam valor financeiro de mercado muito superior ao seu valor patrimonial.

Dentro dessa redefinição experimentada pelo conceito de construção de marca, merece especial destaque o papel das relações públicas. É no processo de comunicação, fundamental para o branding, que a marca assume papel estra- 
tégico fundamental para as organizações. Os aspectos intangíveis que colaboram para a construção de uma marca sólida e a necessidade de esse discurso ser irradiado para todos os públicos da organização tornam os profissionais de relações públicas atores estratégicos para a consolidação da imagem da marca junto aos seus stakeholders e sua consequente valorização de mercado.

Por outro lado, são quase inexistentes as ações de gerenciamento da integridade e da fidelidade à marca por meio do esporte. Como vimos, o esporte oferece uma série de atributos que podem contribuir, de maneira efetiva, na construção de uma marca em sua relação com atividades ou negócios relacionados ao esporte.

As ações de relações públicas, e toda a comunicação em torno delas estruturadas, fornecem às marcas o poder de influenciar consumidores, parceiros, colaboradores e de interferir nos canais de vendas e distribuição. Além disso, mobilizam o interesse dos investidores, transformando o desempenho da organização e seu resultado financeiro.

O branding encontra também no "produto" esporte vasto campo para prosperar. Assim como o processo de edificação de uma marca, o fenômeno esportivo e os produtos dele resultantes apresentam forte participação dos aspectos intangíveis. É na emoção provocada pelo esporte que o branding chamará a atenção dos públicos de interesse de uma marca para os atributos resultantes da experiência emocional vivenciada no fato ou produto esportivo.

\section{RELAÇ̃̃ES PÚBLICAS, MARCAS E LEGADO ESPORTIVO: O CASO DA AMBEV}

O papel dos profissionais de relações públicas, na mediação da exitosa relação existente entre branding e fenômeno esportivo, colocou a área de relações públicas em evidência nos negócios relacionados ao esporte.

A inserção do Brasil na geopolítica dos megaeventos esportivos envolve a responsabilidade pela realização das duas maiores competições do universo esportivo mundial. Junto com essa responsabilidade, os megaeventos canalizaram para o Brasil a expectativas de investimentos em várias áreas e, também, o questionamento a respeito do legado dos dois eventos para a sociedade brasileira. A área de relações públicas aparece como a articuladora de todo este universo. Para ilustrar tudo isto, vamos analisar o caso Ambev (Companhia de Bebidas das Américas) ${ }^{3}$.

3 A Ambev é dona de um portfólio com os seguintes produtos e marcas: Antarctica, Brahma, Bohemia, Skol, Original, Stella Artois; os refrigerantes Guaraná Antarctica, Soda, Pepsi e Sukita, além das inovações H2OH!, Fusion e Antarctica Citrus. A empresa é líder no ranking das cervejarias na América Latina e emprega, somente no Brasil, 32 mil funcionários. No ano 2010, atingiu volume de vendas de 165,14 milhões de hectolitros de bebidas e receita líquida de $R \$ 25$ bilhões, um crescimento de $13,2 \%$ em relação ao ano de 2009 (Ambev, 2011). 
A empresa, de capital aberto, sediada na cidade de São Paulo e com operações em catorze países das Américas ${ }^{4}$, apresentou ao público, no mês de julho de 2011, sua "plataforma de futebol". Esta inclui ações mercadológicas e sociais que pretendem deixar um legado para a prática do esporte no Brasil e, evidentemente, criar um posicionamento favorável para uma de suas marcas, a Brahma, como a "cerveja oficial" da Copa do Mundo de 2014.

A proposta da plataforma é garantir, em parceria com os principais times de futebol do Brasil, ações de apoio às atividades relacionadas ao futebol em conjunto com as agremiações parceiras. A empresa pretende, com isso, reforçar sua atuação no esporte mais popular do país, oferecendo benefícios concretos e permanentes para o futebol. A plataforma, que compreende uma série de iniciativas, visa deixar um legado esportivo e socioambiental para a comunidade esportiva nacional.

Em 2010, ano anterior ao lançamento da plataforma, a empresa já havia fortalecido sua presença no futebol, com o patrocínio de 26 clubes em todo o país. As ações apresentadas em 2011 pretendem beneficiar clubes e torcedores, posicionando favoravelmente a imagem da marca, tendo como objetivo final seu posicionamento mercadológico para a Copa do Mundo de 2014.

Em seu discurso, a empresa apregoa que os objetivos da plataforma transcendem à disputa da principal competição do futebol mundial no Brasil. "A relação da Ambev com os clubes tem um papel fundamental, afinal a Copa do Mundo vem e vai, mas os clubes continuam. E são os clubes que fazem o nosso futebol”, afirma Marcel Marcondes (Ambev, 2011), diretor de Negócios do Esporte da empresa.

Para estreitar relacionamento com os fãs do futebol carioca, o projeto da empresa prevê a realização de uma série de ações ${ }^{5}$ que beneficiarão os quatro principais clubes do Rio de Janeiro. Para divulgar suas ações de ativação e reforçar a experiência do torcedor com seu time de coração, a empresa lançou as redes sociais customizadas para esses quatro clubes no Twitter, no Facebook e

4 A Ambev opera, nas Américas, nos seguintes países: Argentina, Brasil, Bolívia, Canadá, Chile, El Salvador, Equador, Guatemala, Nicarágua, Paraguai, Peru, República Dominicana, Uruguai e Venezuela (Ambev, 2011).

5 A plataforma de futebol da Ambev, para fortalecimento da marca Brahma junto à comunidade do futebol no Rio de Janeiro, "prevê parceria inédita com o Engenhão, com ativações no estádio, como, por exemplo, a manutenção do gramado. Para isso, a marca trabalhará junto com o Botafogo para garantir a qualidade do gramado do estádio. A Brahma assume também, em parceria com o Vasco, a qualidade do gramado de São Januário. Ainda com o clube, a marca está executando a construção da sala de musculação (...). Além disso, entregou o moderno vestiário junto com uma nova sala de imprensa. (...) Com o Flamengo, a marca realiza obras no campo principal do Ninho Urubu, centro de treinamento do clube, e o projeto "Rubro-negro para sempre", para que os flamenguistas deixem seus nomes gravados na história do clube ao adquirirem tijolos personalizados que serão cravados no CT. (...) Outra novidade é a construção da sala de troféus do Fluminense, desenvolvida com alta tecnologia e interatividade, que permitirá ao público rever toda a trajetória do clube. Um painel mostrará todas as camisas históricas do tricolor carioca e o torcedor poderá ouvir músicas de sua torcida referentes ao time" (Ambev, 2011). 
You Tube:@Brahma/Fogo; @BrahmaFla; @BrahmaFlu; e @BrahmaVasco). Nesses canais, o torcedor encontra conteúdos diferenciados, promoções e vídeos referentes às agremiações.

Ações semelhantes àquelas previstas para os clubes da cidade do Rio de Janeiro, também estão programadas para as duas principais agremiações de Belo Horizonte - Atlético e Cruzeiro ${ }^{6}$.

Todos os programas relatados acima procuram cristalizar a marca Brahma dentro do contexto do esporte-desempenho, voltado para o mercado. Para ilustrar as múltiplas possibilidades do fenômeno esportivo enquanto elemento de alicerce para a construção de uma marca, ações voltadas para o esporte-participação e para o esporte-educação também foram contempladas na plataforma proposta pela Ambev.

Para incentivar o futebol nas comunidades paulistanas e da Grande São Paulo,

a marca realiza há quatro anos, em parceria com a Secretaria Municipal de Esportes [da cidade de São Paulo] e a Federação Paulista de Futebol, o Campeonato Paulista de Futebol Amador - a Taça Brahma -. que se consolidou como um importante incentivo ao futebol de várzea do país. O projeto reuniu 128 times de São Paulo e da região metropolitana (Ambev, 2011).

Para comunicar sua preocupação com o legado do esporte no Brasil, a empresa irá utilizar o futebol como agente de transformação socioeconômica em comunidades de baixa renda. O projeto "Brahma na comunidade", lançado em julho de 2011, conta com cinco pilares de atuação: "contribuições e reformas na infraestrutura dos campos de futebol da comunidade; implantação de ações de consumo responsável; desenvolvimento de atividades de lazer e cultura; programas de geração de renda; e reciclagem” (Ambev, 2011).

Para completar o conjunto de ações de fortalecimento da marca Brahma, junto aos seus públicos de interesse, a Ambev investiu, também, no esporte-desempenho. A marca foi a primeira a oferecer ingressos para a Copa do Mundo de 2014. O concurso "Sou brahmeiro, sou primeiro", que deu os vinte primeiros ingressos para o mundial, foi lançado exatamente no mesmo dia em que a cidade do Rio de Janeiro foi sede do sorteio das chaves para as eliminatórias da competição, primeiro evento oficial programado pela Fifa $^{7}$ para a Copa do Mundo, ocorrido em território brasileiro.

6 Após o lançamento de latas decoradas para as torcidas do Cruzeiro e Atlético, a marca irá reformar a sala de imprensa do centro de treinamento do Cruzeiro e, até o final do ano, será feita uma ação com os torcedores para escolha da nova benfeitoria que poderá ser a sala de musculação ou o vestiário. Os novos espaços terão estrutura semelhante aos clubes europeus, proporcionando mais conforto e melhoria no desempenho dos atletas. A parceria da Brahma com o Atlético Mineiro proporcionará reformas e progressos no centro administrativo do Galo. Os projetos estão previstos para o fim deste ano (AMBEV, 2011).

7 Fifa: Federação Internacional de Futebol Associado, entidade que promove e organiza a Copa do Mundo de Futebol. 
Segundo a própria empresa (Ambev, 2011),

somente uma marca como a Brahma, que tem uma longa relação com o futebol, poderia realizar esse concurso. A marca sempre foi uma das principais patrocinadoras do esporte favorito dos brasileiros, realizando ações tanto com os torcedores como também com importantes clubes e jogadores. Ser a primeira marca a oferecer ingressos para a Copa do Mundo de 2014, três anos antes da competição, vem coroar esse posicionamento.

Para uma empresa fabricante de bebida alcoólica pode soar paradoxais todas as ações de investimento em esporte, que trazem como um de seus principais atributos a busca pela vida saudável e com qualidade. Para conscientizar a comunidade do Complexo do Muquiço, na zona norte do Rio de Janeiro, a Brahma, em parceria com o Instituto Bola Pra Frente, iniciativa do tetracampeão mundial de futebol Jorginho, lançou uma campanha de esclarecimento ${ }^{8}$ sobre o consumo responsável e moderado de bebidas alcoólicas.

De qualquer forma, quando analisamos os momentos anteriores de relacionamento da marca com o esporte e o comparamos com aquilo que foi proposto para o período 2011-2014, podemos verificar que as estratégias de comunicação com os stakeholders foram radicalmente modificadas. As isoladas peças publicitárias de copas do mundo anteriores foram transformadas na "plataforma de futebol" do Mundial de 2014. A modificação ocorrida na forma de a empresa enxergar a comunicação mostra o potencial das relações públicas na exitosa articulação das empresas com o fenômeno do esporte.

\section{CONSIDERAÇÕES FINAIS}

O desenvolvimento do branding e a necessidade das grandes corporações mundiais de planejar suas atividades em caráter global colocaram o esporte, por todas as possibilidades que oferece, no centro deste processo.

Pelo seu caráter muitas vezes intangível, pelos atributos positivos que podem, em geral, a ele ser associados, o esporte apresenta, em sua plenitude, uma série de possibilidades para edificação de uma marca forte. Seja em seus aspectos mais sociais - ligados à participação e educação -, seja em seus aspectos de mercado - voltados ao desempenho e à performance -, o esporte auxilia na construção das marcas "nos corações e nas mentes" dos consumidores de produtos e serviços oferecidos ao mercado pelas organizações.

8 "A campanha será divulgada nos bares locais pelas 'mulheres multiplicadoras' - lideranças femininas capacitadas pela equipe técnica do Instituto Bola Pra Frente, com o apoio do Programa Jovens de Responsa, da Ambev. 0 programa é desenvolvido pela companhia em parceria com outras nove organizações não-governamentais além do Bola Pra Frente. As ONGs atuam em São Paulo, Rio de Janeiro e Salvador e o objetivo é evitar o uso abusivo do álcool e o consumo por menores de dezoito anos" (Ambev, 2011). 
O entendimento de que uma marca forte é, hoje, ativo financeiro de uma organização dá ao branding uma importância estratégica. As marcas passam a contribuir, assim, de forma cada vez mais preponderante, para o sucesso de uma empresa. O esporte, como demonstra o caso da Ambev, oferece o cenário perfeito para essa construção estratégica.

Os aspectos intangíveis de uma marca, quando bem gerenciados, dão a ela uma vida perene. Os ativos tangíveis, ao contrário, têm vida útil finita. Além disso, as características físicas de um produto podem ser copiadas rapidamente, o que prejudica, de forma contundente, seu resultado econômico e financeiro. Em contrapartida, os aspectos intangíveis de uma marca não podem ser reproduzidos.

A boa gestão de uma marca passa pela administração de seu impacto na estratégia, estrutura e cultura da empresa, como forma de, consistentemente, garantir a promessa e proposta de valor aos seus stakeholders, incluindo consumidores, distribuição e canal de venda.

Dentro desse contexto, nada melhor, como já vimos, do que o fenômeno esportivo para a edificação da cultura e "do estilo de vida", dos valores, enfim, de uma marca. A Copa do Mundo de 2014 e os Jogos Olímpicos de 2016, ambos no Brasil, serão as vitrines para a concretização, cada vez mais intensa, dessa feliz trilogia envolvendo relações públicas, branding e esporte.

\section{REFERÊNCIAS}

AMBEV. Ambev apresenta oficialmente sua plataforma de futebol. 12/07/2011. Disponível em: <http://www.ambev.com.br>. Acesso em: 17 set. 2011.

BRACHT, Valter. Sociologia crítica do esporte: uma introdução. ljuí: Unijuí, 2011.

DA SILVA, José. Gestão da segurança pública em megaeventos esportivos. In: DaCOSTA, Lamartine Pereira (Org.). Atlas do esporte no Brasil: atlas do esporte; educação física e atividades físicas de saúde e lazer no Brasil. Rio de Janeiro: Shape, 2005. Também disponível em: <http://www.atlasesportebrasil.org.br/index.php>.

KUNSCH, Margarida M. Krohling. Comunicação organizacional. Vol. 1. Histórico, fundamentos e processos. São Paulo: Saraiva, 2009. MELO NETO, Francisco de Paula; CARVALHO, Sérgio. Gestão de marcas nos esportes: teoria e prática. Jundiaí: Fontoura, 2006. MORGAN, Melissa Johnson; SUMMERS, Jane. Marketing esportivo. São Paulo: Thomson, 2008.

MULLIN, Bernard J.; HARDY, Stephen; SUTTON, William A. Marketing esportivo. Porto Alegre: Artmed, 2004.

NICOLINI, Henrique. 0 evento esportivo como objeto de marketing. São Paulo: Phorte Editora, 2009.

PITTS, Brenda G.; STOTLAR, David K. Fundamentos de marketing esportivo. São Paulo: Phorte Editora, 2002.

RUFINO, Andressa. Arena multiuso: um novo campo de negócios. São Paulo: Trevisan, 2010.

ZENONE, Luiz Cláudio. Marketing social. São Paulo: Thomson, 2006.

Recebido em: 27.09.2011 / Aceito em: 21.10.2011 